\title{
Comment on "Breast cancer-related lymphedema: quality of life after lymph node transfer"
}

\begin{abstract}
Azra Ashraf
Affiliates in Plastic Surgery, Mclean, VA 22101, USA. 2016;3:320-1.

Article history: Received: 26-08-2016

Accepted: 06-09-2016

As plastic surgeons, improvements in quality of life are often the goal of our labor. As the vascularized lymph node transfer (VLNT) procedure continues to evolve to become the surgical solution for lymphedema, proving the efficacy not only as a technique, but equally as important, its impact on quality of life is pivotal. De Brucker et al. ${ }^{[1]}$ elegantly demonstrates quality improvements during a 29-month postoperative duration through a validated survey (Upper Limb Lymphedema-27 Questionnaire).
\end{abstract}

Correspondence to: Dr. Azra Ashraf, Affiliates in Plastic Surgery, Mclean, VA 22101, USA. E-mail: azra.ashraf@gmail.com

How to cite this article: Ashraf A. Comment on "Breast cancer-related lymphedema: quality of life after lymph node transfer". Plast Aesthet Res

Published: 30-09-2016

Although I largely agree with the results and the study design, I speculate recall bias may be high. In this study, patients received 2 Upper Limb Lymphedema-27 Questionnaires postoperatively. Though the surveys were identical, one was to be completed based on the patients' pre-operative status (a duration of up to 5 years previously). In addition, 22 patients of the 25 patients underwent simultaneous procedures (DIEP \& lymph node transfer), combining the risk, morbidity and ultimately the patient's experience of 2 separate procedures. This may have implications in recall bias because of the resultant limitation when comparing seemingly identical procedures. Though it is certainly reasonable to perform lymph node transfer simultaneously as part of breast reconstruction, when attempting to study the experiential effect of lymph node transfer in situ, it's difficult to delineate.

In my experience, breast reconstruction is an integral component of patients' wellbeing. With the prevalence of breast cancer-related lymphedema up to $49 \%,{ }^{[2]}$ it is critical we seek a surgical solution. As the field of lymph node transfer continues to mature your study is the first to demonstrate an improvement in quality of life via a validated survey and furthermore sets the foundation that VLNT improves wellbeing and functionality in this patient population.

\section{Financial support and sponsorship} None.

\section{Conflicts of interest}

There are no conflicts of interest.

\section{Patient consent}

Not involved.

\section{Ethics approval}

Not involved. 


\section{REFERENCES}

1. De Brucker B, Zeltzer A, Seidenstuecker K, Hendrickx B, Adriaenssens N, Hamdi M. Breast cancer-related lymphedema: quality of life after lymph node transfer. Plast Reconstr Surg 2016;137:1673-80.
2. Veronesi U, Paganelli G, Viale G, Luini A, Zurrida S, Galimberti V, Intra M, Veronesi P, Robertson C, Maisonneuve P, Renne G, De Cicco C, De Lucia F, Gennari R. A randomized comparison of sentinel node biopsy with routine axillary dissection in breast cancer. $N$ Engl $J$ Med 2003;349:546-53. 